\title{
Prevalence of hallux valgus in the general population: a systematic review and meta- analysis
}

Sheree Nix, Michelle Smith*, Bill Vicenzino

\begin{abstract}
Background: Hallux valgus (HV) is a foot deformity commonly seen in medical practice, often accompanied by significant functional disability and foot pain. Despite frequent mention in a diverse body of literature, a precise estimate of the prevalence of $\mathrm{HV}$ is difficult to ascertain. The purpose of this systematic review was to investigate prevalence of $\mathrm{HV}$ in the overall population and evaluate the influence of age and gender.

Methods: Electronic databases (Medline, Embase, and CINAHL) and reference lists of included papers were searched to June 2009 for papers on HV prevalence without language restriction. MeSH terms and keywords were used relating to HV or bunions, prevalence and various synonyms. Included studies were surveys reporting original data for prevalence of HV or bunions in healthy populations of any age group. Surveys reporting prevalence data grouped with other foot deformities and in specific disease groups (e.g. rheumatoid arthritis, diabetes) were excluded. Two independent investigators quality rated all included papers on the Epidemiological Appraisal Instrument. Data on raw prevalence, population studied and methodology were extracted. Prevalence proportions and the standard error were calculated, and meta-analysis was performed using a random effects model.

Results: A total of 78 papers reporting results of 76 surveys (total 496,957 participants) were included and grouped by study population for meta-analysis. Pooled prevalence estimates for HV were $23 \%$ in adults aged 18-65 years (Cl: 16.3 to 29.6$)$ and $35.7 \%$ in elderly people aged over 65 years ( $\mathrm{Cl}: 29.5$ to 42.0). Prevalence increased with age and was higher in females [30\% (Cl: 22 to 38)] compared to males [13\% (Cl: 9 to 17)]. Potential sources of bias were sampling method, study quality and method of HV diagnosis.

Conclusions: Notwithstanding the wide variation in estimates, it is evident that $\mathrm{HV}$ is prevalent; more so in females and with increasing age. Methodological quality issues need to be addressed in interpreting reports in the literature and in future research.
\end{abstract}

\section{Background}

Hallux valgus (HV) is one of the most common chronic foot complaints presenting to foot and ankle specialists [1], occurring when the hallux deviates laterally towards the other toes, and the first metatarsal head becomes prominent medially [2]. As well as being a major contributor to the costs for forefoot surgery, HV has been linked to functional disability, including foot pain [3], impaired gait patterns [4], poor balance [5], and falls in older adults [6,7].

\footnotetext{
* Correspondence: m.smith5@uq.edu.au

Division of Physiotherapy, School of Health and Rehabilitation Sciences, The University of Queensland, Brisbane, Australia
}

Although HV has gained substantial attention in both historic and recent literature, several authors have highlighted the fact that a true prevalence estimate for $\mathrm{HV}$ is difficult to ascertain $[8,9]$. A wide range of prevalence estimates for HV has been presented in a multitude of independent reports. National health surveys in the United States have reported a prevalence of $0.9 \%$ across all age groups [10], while a more recent survey in the UK reported a prevalence of $28.4 \%$ in adults [9]. Research conducted in elderly populations has indicated prevalence rates as high as 74\% [11]. Individual studies have reported that $\mathrm{HV}$ is more common in female and elderly individuals $[9,12]$; however, there has been no synthesis of the literature to date or synopsis derived. 
Due to the lack of firm epidemiological data relating to $\mathrm{HV}$, it is difficult to estimate the impact that this condition has on the population; thus, in order to establish the need for future research, a better understanding of HV prevalence is warranted. To date there has been no published systematic review investigating the prevalence of HV and the influence of age and gender. Therefore, the aim of this systematic review and meta-analysis was to examine HV prevalence in the overall population and in age and gender subgroups.

\section{Methods}

\section{Data sources}

Electronic databases (Medline, Embase, and CINAHL) were searched by the first author for all years available up to June 2009 to identify all publications discussing HV prevalence. Broad MeSH terms and keywords were used combining the following: the condition of interest (e.g. bunion or hallux valgus or great toe deformity or foot deformity or foot problem) and epidemiological terms (e. g. questionnaire or survey or prevalence or incidence). For the full search syntax with truncation used for each database refer to Additional file 1 (Additional file 1.xls). Reference lists of all included papers were hand-searched to identify grey literature (i.e. government publications and theses), articles that were too old to be indexed on electronic databases, and articles without abstracts that were missed by the initial search strategy.

\section{Study selection}

All titles and abstracts retrieved by the above search strategy were scanned by the first author using an initial screening question: Does the article appear to discuss prevalence of hallux valgus or bunions? The full text was sourced if required, and the same author undertook detailed eligibility assessment using pre-determined criteria based on HV diagnosis (including both clinically diagnosed HV and self-reported bunions), study design, and reports of original quantitative data for HV prevalence (Figure 1). Surveys of specific disease groups (e.g. rheumatoid arthritis or diabetes), intervention studies, and studies where prevalence data was grouped with other foot deformities were excluded. As this review was not restricted to the English language, translations were sourced for articles written in German, Russian, Spanish, Serbian, Turkish, and Chinese.

\section{Quality assessment}

Papers were scored for quality by two independent assessors using the Epidemiological Appraisal Instrument (EAI) [13], which has been shown to be a reliable and valid tool for assessing observational studies. Items not applicable to cross-sectional study designs were removed, resulting in a 17 -item scale. Title, author and journal details were removed to de-identify articles prior to rating. Disagreements between the two assessors were resolved by consultation with a third party. Each item was scored as either "Yes" (score $=2$ ), "Partial" (score = $1)$, "No" (score $=0)$, "Unable to determine" (score $=0)$, or "Not Applicable" (item was removed from scoring). Detailed criteria to determine each response were modified from the original instrument and agreed upon by all assessors prior to rating. The overall score was derived as an average of the scores for all 17 items (range 0-2). Studies were then classified as either "high" or "low" quality using the median quality score (0.91).

\section{Data extraction}

Data extraction was performed by the first author, and queries discussed and resolved by all authors in regular meetings. Prevalence data were extracted for each study population and converted to raw counts of individuals with HV. Raw prevalence data for age and gender subgroups was also extracted separately wherever possible, as previously published literature has suggested that $\mathrm{HV}$ prevalence varies with these factors [9]. Authors were contacted where additional information was required.

\section{Statistical methods}

The summary statistic for each study or subgroup was a prevalence proportion, calculated as the ratio of the number of individuals with HV to the sample size of that study or subgroup. The standard error for each prevalence estimate was then calculated. Meta-analysis was performed to obtain pooled prevalence estimates using a random effects model, which gives an average estimate across studies weighted by sample size. A Chi-squared test was used to determine heterogeneity across studies. Due to the diversity of study populations, prevalence estimates were only pooled between studies with similar age and gender characteristics. For the purposes of this age subgroup analysis, we categorised age by three broad categories: juvenile ( $<18$ years), adult (18-65 years), and elderly ( $>65$ years). Studies in which the sample did not exactly fall within one of these age categories were categorised independently by each author, and if a consensus could not be reached data were excluded from the age subgroup analysis.

The subgroup (24 studies) that reported HV prevalence for the overall population (i.e. all ages included in their sample, and a prevalence estimate given that was not split by gender or age) was further analysed for potential sources of bias. Studies were grouped according to sampling method, definition of $\mathrm{HV}$, and study quality to determine if these factors influenced prevalence estimates. Influence of sample size and publication year were investigated by funnel plots. All analyses were performed using Stata version 10 [14]. 


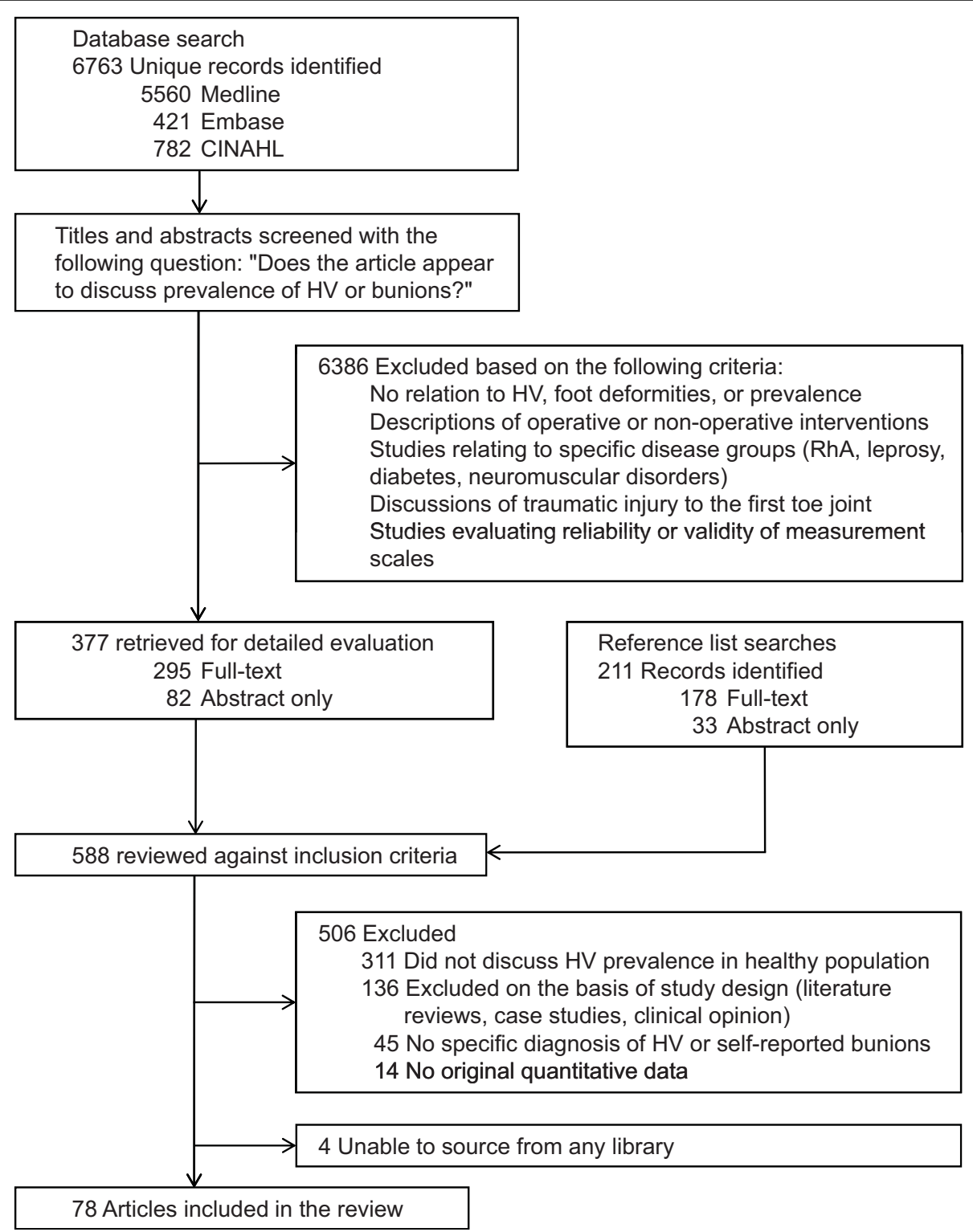

Figure 1 Selection process for inclusion of articles in the review.

\section{Results}

\section{Database search}

The database search yielded a total of 8456 hits, from which 1693 were removed as duplicates. The remaining 6763 citations were scanned by title and abstract, and 377 potentially relevant records were identified. Fiftyseven of these satisfied all eligibility criteria and gave original data for $\mathrm{HV}$ prevalence. Hand-searching of reference lists yielded another 211 potentially relevant titles, of which 21 met all eligibility criteria and were included in the review. A total of 78 papers were included and underwent quality assessment (Figure 1). Papers that reported on the same sample as a previously published study $(n=7)$ were only included once in the analysis. Four papers reported data from more than one sample population; thus, data were extracted from a total of 76 studies (total 496,957 participants). One author was contacted to provide clarification that multiple papers reported data from the same sample. Another author who only provided graphical data for age and gender subgroups was also contacted during data extraction.

\section{Study characteristics}

Selected characteristics of all studies included in the review can be found in Additional file 2 (Additional file 2. $x l s$ ). Study characteristics varied widely in terms of study population and methodology. Twenty-eight studies 
(37\%) were conducted in the USA, 21 (28\%) in the UK, $8(10 \%)$ in Australia, and $4(5 \%)$ in Germany, with the remaining 15 studies (20\%) conducted in other regions. More than half of studies (66\%) conducted a clinical examination, while others utilised interviews (13\%) or questionnaires (7\%) to gather self-report data. Fifteen studies (20\%) were published after the year 2000, and 19 studies (25\%) were published before 1970. Sample sizes varied widely, with the smallest sample reported being 30 individuals [15], and the largest sample being 197,422 individuals surveyed in a US National Health Survey [16].

\section{Quality assessment}

Overall agreement for rating of quality of reporting and methodology between the two assessors was $87 \%$. The results from the quality assessment can be found in Additional file 3 (Additional file 3.xls). The quality assessment revealed that only 18 studies (24\%) used a random sampling method, only $39 \%$ of studies adequately described their sampling frame, and less than half of studies (47\%) provided a simple description of study participant characteristics, such as age and gender. Despite the importance of a clear definition of HV, only twelve studies (16\%) defined HV according to angular criteria. Reliability and validity of measurement methods were described in only five (7\%) and four (5\%) studies, respectively.

\section{Meta-analysis}

Studies included in the meta-analysis, grouped by age of study population, are listed in Additional file 4 (Additional file 4.xls). Meta-analysis by age subgroups revealed a prevalence of $23 \%$ (CI: 16.3 to 29.6) in adults aged 18-65 years (15 studies), and HV prevalence clearly increased with age (Table 1). Studies that reported HV prevalence by gender consistently showed a higher prevalence of $\mathrm{HV}$ in females [30\% (CI: 22 to 38)] (23 studies) compared to males [13\% (CI: 9 to 17)] (22 studies) (Figure 2). However, there was a high degree of heterogeneity between studies in all subgroups $\left(\chi^{2} 156.55\right.$ to 3213.78; $p<0.0001 ; \mathrm{I}^{2}=95.8 \%$ to $\left.99.6 \%\right)$.

Finally, prevalence estimates were influenced by method of HV diagnosis (self-report or clinically diagnosed), sampling methods (random, convenience, or biased) and study quality. Studies using self-report data and random sampling methods, as well as those with high quality scores on the EAI reported lower prevalence estimates. There was no consistent trend apparent with regard to sample size or publication year (Figure 3).

\section{Discussion}

This review revealed a wide variation in $\mathrm{HV}$ prevalence estimates, and meta-analysis showed that systematic
Table 1 Pooled random effects estimates for HV prevalence by age subgroup expressed as \% $(95 \% \mathrm{Cl})$

\begin{tabular}{|c|c|c|c|}
\hline & Overall & Male & Female \\
\hline \multicolumn{4}{|l|}{ Juvenile } \\
\hline $\begin{array}{l}\text { Pooled prevalence } \\
\text { estimate }\end{array}$ & $\begin{array}{l}7.8 \\
(6.2 \text { to } 9.5)\end{array}$ & $\begin{array}{l}5.7 \\
\text { (3.7 to } 7.6)\end{array}$ & $\begin{array}{l}15.0 \\
(7.7 \text { to } 22.3)\end{array}$ \\
\hline Number of studies & 16 & 5 & 6 \\
\hline \multicolumn{4}{|l|}{ Adult } \\
\hline $\begin{array}{l}\text { Pooled prevalence } \\
\text { estimate }\end{array}$ & $\begin{array}{l}23.0 \\
(16.3 \text { to } 29.6)\end{array}$ & $\begin{array}{l}8.5 \\
(1.4 \text { to } 15.6)\end{array}$ & $\begin{array}{l}26.3 \\
(16.5 \text { to } 36.2)\end{array}$ \\
\hline Number of studies & 15 & 8 & 9 \\
\hline \multicolumn{4}{|l|}{ Elderly } \\
\hline $\begin{array}{l}\text { Pooled prevalence } \\
\text { estimate }\end{array}$ & $\begin{array}{l}35.7 \\
\text { (29.5 to } 42.0)\end{array}$ & $\begin{array}{l}16.0 \\
\text { (10.6 to } 21.3)\end{array}$ & $\begin{array}{l}36.0 \\
(26.9 \text { to } 45.1)\end{array}$ \\
\hline Number of studies & 37 & 16 & 16 \\
\hline
\end{tabular}

differences in these estimates were related to a number of factors, including method of HV diagnosis, gender, age, study quality, and sampling method. The finding that substantial differences may be related to the method of HV diagnosis (i.e. self-report or clinical examination) (Figure 3), confirms the results of a number of studies that have shown lower prevalence rates with the self-report methods commonly used in largescale surveys when directly compared to clinical examination [17-22]. Prevalence of HV may therefore be under-reported in epidemiological surveys that rely on self-report data.

Systematic differences according to gender and age were clearly demonstrated by our meta-analysis. The pooled estimate of $\mathrm{HV}$ prevalence in females (30\%) was 2.3 times greater than the estimate for males (13\%). This supports the observation of several individual reports that $\mathrm{HV}$ is more prevalent in females. For example, a recent large-scale epidemiological study of people older than 30 years reported a prevalence of $38 \%$ in women compared to $21 \%$ in men [9], and another recent survey of older adults reported a prevalence of $58 \%$ in women and $25 \%$ in men [12]. The trend for an increase in HV prevalence with age was also demonstrated by our data: $7.8 \%$ in juveniles (16 studies, $\mathrm{n}=73,030$ ), $23 \%$ in adults aged $18-65$ years ( 15 studies, $\mathrm{n}=23,790)$ and $35.7 \%$ in the elderly (37 studies, $\mathrm{n}=16,001$ ) (Table 1 ).

Variations in reported prevalence of $\mathrm{HV}$ in previous literature may also be explained by differences in study quality and methodological issues, particularly sampling bias (Figure 3). We identified a trend for higher prevalence estimates from studies with low quality scores on the EAI (score <0.91). Higher prevalence estimates were also reported by studies using convenience samples [23-29] or biased samples of people seeking treatment for foot problems $[15,30,31]$, in comparison to those 


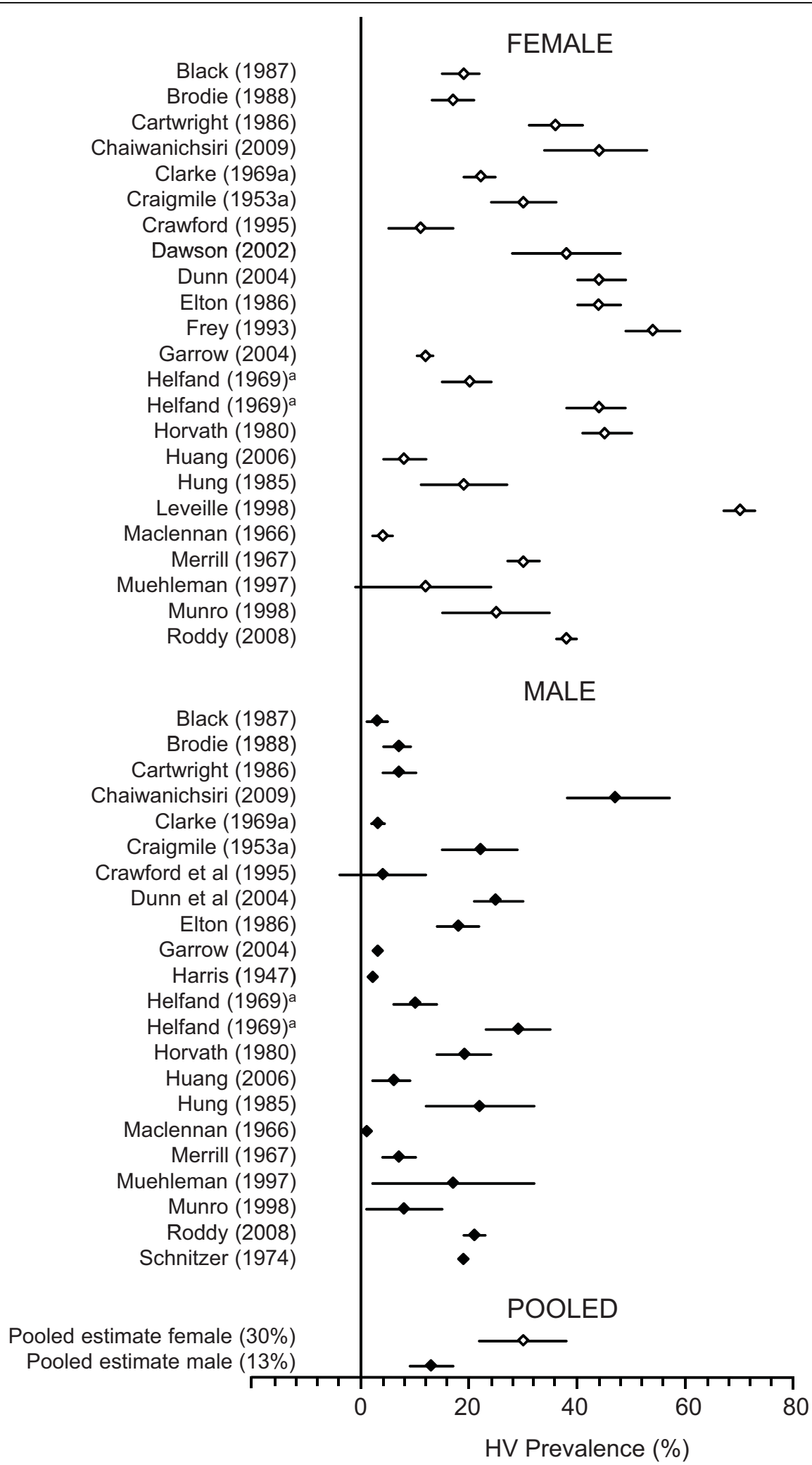

Figure 2 HV prevalence estimates by gender. Diamonds indicate prevalence estimates by male (black diamonds) and female (white diamonds) subgroups, with bars representing 95\% confidence intervals. ${ }^{a}$ Study reported more than one prevalence estimate based on different diagnostic methods in the same sample population (self-reported vs. clinically diagnosed HV). 


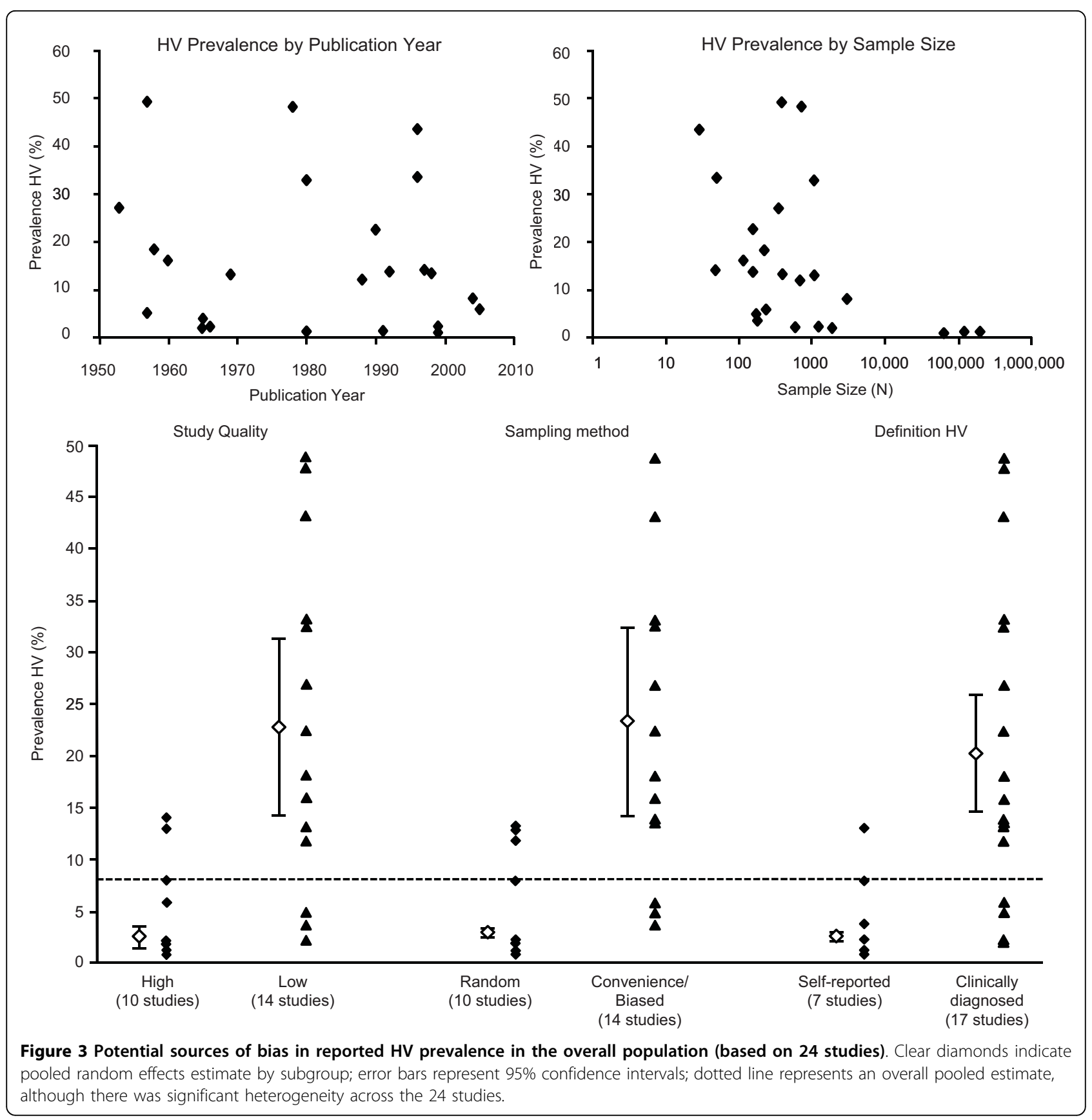

studies that used random sampling from the general population [10,16,32-39]. Potential bias may be introduced by lower quality studies with sampling bias; however, as discussed previously, this trend may also be related to the fact that these "low" quality studies were mostly clinical studies that diagnosed HV rather than relying on self-report data.

Our findings should be considered in light of several limitations in the available literature concerning HV. One major concern is the lack of a clearly stated definition of $\mathrm{HV}$ in the majority of studies reviewed. Even in those studies where HV was observed on clinical examination, very few described a quantifiable method of measuring HV. Only $16 \%$ of studies in our review defined a diagnosis of $\mathrm{HV}$ using angular criteria measured clinically or on $\mathrm{x}$-ray. A few more recent studies used the Manchester Scale, a categorical scale based on standardised photographs with four gradings to classify HV severity [40-43]. Of those studies that collected self-reported prevalence data via interview or 
questionnaire, only a few provided participants with a definition or diagram of HV $[9,35,44]$. In addition, there is confusion surrounding the interchangeable use of the terms "bunion" and "hallux valgus." In this review both terms were considered to represent $\mathrm{HV}$; however, the term "bunion" strictly refers to the medial bursitis that may develop over the first metatarsal head as a result of irritation [1]. Most included studies that used self-report data asked subjects about "bunions"; undoubtedly, a poor understanding of the terms used in a questionnaire or interview will result in inaccurate self-report data. Finally, there has been poor reporting of the reliability and validity of methods used to diagnose HV. Clearly, for accurate prevalence data to be collected and compared across different populations a consistent definition of $\mathrm{HV}$ and validated measurements should be employed.

Another consideration for our meta-analysis was the statistically significant degree of heterogeneity or variation across studies. Wide variations in sample populations meant that much of the retrieved data could not be pooled; however, pooling of estimates across age and gender subgroups was considered to be an important synopsis of the available literature pertaining to HV. Our subgroup meta-analysis was limited by the fact that not all studies reported HV prevalence by gender or age. Those studies that did report prevalence by age used a range of different age groupings, which rendered impossible further sub grouping the 18-65 years age bracket. Our analysis of potential sources of bias (Figure 3) was conducted to attempt to explain this variation between studies and highlight possible sources of heterogeneity.

Finally, insufficient data was available to examine the influence or adjust for other factors such as ethnicity, geographic location, shoe wearing or socioeconomic status on HV prevalence. Details of sampling frame and sample characteristics were also often poorly reported, as revealed by our quality assessment (Additional file 3 Additional File 3.xls). The vast majority of studies did not report on the presence of symptoms (i.e. pain or disability) related to $\mathrm{HV}$, and therefore this factor could not be investigated by our review.

Having highlighted the limitations of the currently available epidemiological data relating to $\mathrm{HV}$, further large-scale epidemiological studies are clearly warranted. Future studies should utilise rigorous methods, including random sampling from the general population and from different ethnic and socioeconomic groups. Validated tools should be used to diagnose HV, and results should be reported by gender and age as these factors are known to be associated with HV prevalence. Information relating to the presence of symptomatic versus asymptomatic HV would also be of great benefit in determining the impact of HV on the general population. Clear reporting of all these factors in future studies will provide an evidence base that will enhance our understanding of the impact of $\mathrm{HV}$ on the population and the health care system, and subsequently assist with the delivery of appropriate treatment. Due to its prevalence in the aging population, further research should focus on the impact of HV on mobility and quality of life in the elderly.

\section{Conclusions}

This meta-analysis reveals a high prevalence of HV in the overall population and highlights the wide variation in prevalence estimates across studies. Our results also support the commonly held view that HV is more prevalent in women and the elderly. This study has highlighted the issues that make it difficult to provide a true estimate of $\mathrm{HV}$ prevalence in the general population, with recommendations for future research.

\section{Additional material}

\section{Additional file 1: Search syntax used for electronic databases. \\ Additional file 2: Selected characteristics of papers included in systematic review $[4,5,9-11,15-38,37-40,42-87]$. \\ Additional file 3: Results from quality assessment}

Additional file 4: Studies included in meta-analysis, grouped by age of study population.

\section{Acknowledgements}

Funding/Support: SN is currently supported by an Australian Postgraduate Award Scholarship at The University of Queensland, and funding for the cost of language translation was provided by the School of Health and Rehabilitation Sciences, The University of Queensland.

Additional Contributions: We thank Dr Asad Khan, PhD (School of Health and Rehabilitation Sciences, The University of Queensland) for his statistical advice in this meta-analysis.

\section{Authors' contributions}

All authors contributed equally to the conception and design of this study. SN carried out literature searches, quality assessments, data extraction and statistical analysis and was responsible for drafting of the manuscript. MS also carried out quality assessments. MS and BV were responsible for supervision, including interpretation of data and critical revision of the manuscript. All authors read and approved the final manuscript.

\section{Competing interests}

The authors declare that they have no competing interests.

Received: 3 June 2010 Accepted: 27 September 2010

Published: 27 September 2010

\section{References}

1. Vanore JV, Christensen JC, Kravitz SR, Schuberth JM, Thomas JL, Weil LS, Zlotoff HJ, Couture SD: Diagnosis and treatment of First Metatarsophalangeal Joint Disorders. Section 1: Hallux valgus. J Foot Ankle Surg 2003, 42:112-123.

2. Mann RA, Coughlin MJ: Adult Hallux Valgus. In Surgery of the Foot and Ankle. Edited by: Coughlin MJ, Mann RA. St. Louis: Mosby; , 7 1999:1:150-175.

3. Benvenuti F, Ferrucci L, Guralnik JM, Gangemi S, Baroni A: Foot pain and disability in older persons: an epidemiologic survey. J Am Geriatr Soc 1995, 43:479-484. 
4. Menz HB, Lord SR: Gait instability in older people with hallux valgus. Foot Ankle 2005, 26:483-489.

5. Menz HB, Lord SR: The contribution of foot problems to mobility impairment and falls in community-dwelling older people. J Am Geriatr Soc 2001, 49:1651-1656.

6. Koski K, Luukinen H, Laippala P, Kivela SL: Physiological factors and medications as predictors of injurious falls by elderly people: a prospective population-based study. Age Ageing 1996, 25:29-38.

7. Tinetti ME, Speechley $M$, Ginter SF: Risk factors for falls among elderly persons living in the community. N Engl J Med 1988, 319:1701-1707.

8. Menz HB, Munteanu SE: Radiographic validation of the Manchester scale for the classification of hallux valgus deformity. Rheumatology 2005, 44:1061-1066.

9. Roddy E, Zhang W, Doherty M: Prevalence and associations of hallux valgus in a primary care population. Arthritis Rheum 2008, 59:857-862.

10. Adams PF, Hendershot GE, Marano MA: Current estimates from the National Health Interview Survey, 1996. National Center for Health Statistics. Vital Health Stat 10 1999, 1-203.

11. Menz HB, Lord SR: Foot pain impairs balance and functional ability in community-dwelling older people. J Am Podiatr Med Assoc 2001, 91:222-229.

12. Nguyen USDT, Hillstrom HJ, Li W, Dufour AB, Kiel DP, Procter-Gray E, Gagnon MM, Hannan MT: Factors associated with hallux valgus in a population-based study of older women and men: the MOBILIZE Boston Study. Osteoarthritis Cartilage 2010, 18:41-46.

13. Genaidy AM, Lemasters GK, Lockey J, Succop P, Deddens J, Sobeih T, Dunning K: An epidemiological appraisal instrument - a tool for evaluation of epidemiological studies. Ergonomics 2007, 50:920-960.

14. StataCorp: Stata Statistical Software: Release 10 College Station, TX: StataCorp LP 2007

15. Robbins JM, Roth LS, Villanueva MC: "Stand down for the homeless". Podiatric screening of a homeless population in Cleveland. J Am Podiatr Med Assoc 1996, 86:275-279.

16. Wilder MH: Prevalence of chronic skin and musculoskeletal conditions, United States, 1969. National Center for Health Statistics. Vital Health Stat 10 1980, 1-65.

17. Cartwright A, Henderson G: More Trouble with Feet: A Survey of the Foot Problems and Chiropody Needs of the Elderly London: HMSO Publications Centre 1986.

18. Helfand AE: A study in podogeriatrics: a pilot study of foot problems in the aged and chronically ill. J Am Podiatry Assoc 1963, 53:655-662.

19. Helfand AE: The foot of South Mountain: a foot health survey of the residents of a state geriatric institution. J Am Podiatry Assoc 1969, 59:133-139.

20. Helfand AE: Foot problems in older patients: a focused podogeriatric assessment study in ambulatory care. J Am Podiatr Med Assoc 2004, 94:293-304.

21. Helfand $A E$, Cooke HL, Walinsky MD, Demp PH: Foot problems associated with older patients. A focused podogeriatric study. J Am Podiatr Med Assoc 1998, 88:237-241.

22. Helfand AE, Cooke HL, Walinsky MD, Demp PH, Snyder Phillips B: Foot pain and disability in older persons. Pilot study in assessment and education. J Am Podiatr Med Assoc 1996, 86:93-98.

23. Craigmile DA: Incidence, origin, and prevention of certain foot defects. $\mathrm{Br}$ Med J 1953, 2:749-752.

24. Fridland MO, Tverdynin MS: Role of osteoarthrosis in the development of hallux valgus. Ortop Travmatol Protez 1960, 21:16-20.

25. Hughes J, Clark P, Klenerman L: The importance of the toes in walking. $J$ Bone Joint Surg Br 1990, 72:245-251.

26. Mays SA: Paleopathological study of hallux valgus. Am J Epidemiol 2005, 126:139-149.

27. Morris JB, Brash LF, Hird MD: Chiropodial survey of geriatric and psychiatric hospital in-patients-Angus District. Health Bull (Edinb) 1978 36:241-250.

28. Muehleman C, Bareither D, Huch K, Cole AA, Kuettner KE: Prevalence of degenerative morphological changes in the joints of the lower extremity. Osteoarthritis Cartilage 1997, 5:23-37.

29. Sim-Fook LAM, Hodgson AR: A Comparison of Foot Forms Among the Non-Shoe and Shoe-Wearing Chinese Population. J Bone Joint Surg Am 1958, 40:1058-1062.

30. Durman DC: Metatarsus primus varus and hallux valgus. AMA Arch Surg 1957, 74:128-135.
31. Jones RO, Christenson CJ, Lednar WM: Podiatric utilization referral patterns at an Army medical center. Mil Med 1992, 157:7-11.

32. Adams PF, Benson V: Current estimates from the National Health Interview Survey. National Center for Health Statistics. Vital Health Stat 10 1991, 1-212.

33. Brodie $B S$, Rees $C L$, Robins $D J$ : Wessex feet: a regional foot health survey. Chiropodist 1988, 43:152-165.

34. Clarke M: Trouble With Feet London: G. Bell and Sons, Ltd 1969.

35. Garrow AP, Silman AJ, Macfarlane GJ: The Cheshire Foot Pain and Disability Survey: a population survey assessing prevalence and associations. Pain 2004, 110:378-384.

36. Maclennan R: Prevalence of hallux valgus in a neolithic New Guinea population. Lancet 1966, 1:1398-1400

37. Marr S, Berry G, Wood G, Stevenson M, Cole J: Foot and boot problems of miners working underground. J Occup Health Saf Aust NZ 1998, 14:255-257.

38. Nancarrow SA: Reported rates of foot problems in rural south-east Queensland. Australasian J Podiatric Med 1999, 33:45-50.

39. Shine IB: Incidence of Hallux Valgus in a Partially Shoe-Wearing Community. Br Med J 1965, 1:1648-1650.

40. Chaiwanichsiri D, Janchai S, Tantisiriwat N: Foot disorders and falls in older persons. Gerontology 2009, 55:296-302.

41. Menz HB, Morris ME: Clinical determinants of plantar forces and pressures during walking in older people. Gait Posture 2006 24:229-236.

42. Menz HB, Zammit GV, Munteanu SE: Plantar pressures are higher under callused regions of the foot in older people. Clin Exp Dermatol 2007, 32:375-380.

43. Scott $G$, Menz HB, Newcombe L: Age-related differences in foot structure and function. Gait Posture 2007, 26:68-75

44. Keegan THM, Kelsey JL, Sidney S, Quesenberry CP Jr: Foot problems as risk factors of fractures. Am J Epidemiol 2002, 155:926-931.

45. Al-Abdulwahab SS, Al-Dosry RD: Hallux valgus and preferred shoe types among young healthy Saudi Arabian females. Ann Saudi Med 2000, 20:319-321.

46. Anonymous: An assessment of foot health problems and related health manpower utilization and requirements. J Am Podiatry Assoc 1977. 67:102-114.

47. Badlissi F, Dunn JE, Link CL, Keysor JJ, McKinlay JB, Felson DT: Foot musculoskeletal disorders, pain, and foot-related functional limitation in older persons. J Am Geriatr Soc 2005, 53:1029-1033.

48. Black JR, Hale WE: Prevalence of foot complaints in the elderly. J Am Podiatr Med Assoc 1987, 77:308-311.

49. Cho NH, Kim S, Kwon DJ, Kim HA: The prevalence of hallux valgus and its association with foot pain and function in a rural Korean community. J Bone Joint Surg Br 2009, 91:494-498.

50. Cole AE: Foot inspection of the school child. J Am Podiatry Assoc 1959, 49:446-454.

51. Conrad D: Foot education and screening programs for the elderly. $J$ Gerontol Nurs 1977, 3:11, 14-15.

52. Cramer JS, Forrest K: A survey of deployed foot problems in a desert environment. Mil Med 2008, 173:359-361.

53. Crawford VL, Ashford RL, McPeake B, Stout RW: Conservative podiatric medicine and disability in elderly people. J Am Podiatr Med Assoc 1995, 85:255-259.

54. Dawson J, Thorogood M, Marks S-A, Juszczak E, Dodd C, Lavis G, Fitzpatrick $R$ : The prevalence of foot problems in older women: a cause for concern. J Public Health Med 2002, 24:77-84.

55. Denvir VJ: A school foot health service after 10 years. Chiropodist 1972 , 27:291-301.

56. Dunn JE, Link CL, Felson DT, Crincoli MG, Keysor JJ, McKinlay JB: Prevalence of foot and ankle conditions in a multiethnic community sample of older adults. Am J Epidemiol 2004, 159:491-498.

57. Ebrahim SB, Sainsbury R, Watson S: Foot problems of the elderly: a hospital survey. Br Med J 1981, 283:949-950.

58. Elton PJ, Sanderson SP: A chiropodial survey of elderly persons over 65 years in the community. Public Health 1986, 100:219-222.

59. Emslie M: Prevention of foot deformities in children. Lancet 1939, 234:1260-1263.

60. Enwemeka CS: Physical deformities in Nigerian schools: the Port Harcourt Cohort study. Int J Rehabil Res 1984, 7:163-172. 
61. Evans SL, Nixon BP, Lee I, Yee D, Mooradian AD: The prevalence and nature of podiatric problems in elderly diabetic patients. J Am Geriatr Soc 1991, 39:241-245.

62. Frey C, Thompson F, Smith J, Sanders M, Horstman H: American Orthopaedic Foot and Ankle Society women's shoe survey. Foot Ankle 1993, 14:78-81.

63. Greenberg L: Foot care data from two recent nationwide surveys. A comparative analysis. J Am Podiatr Med Assoc 1994, 84:365-370.

64. Greenberg L, Davis H: Foot problems in the US. The 1990 National Health Interview Survey. J Am Podiatr Med Assoc 1993, 83:475-483.

65. Harris Rl, Beath T: Army Foot Survey. An investigation of foot ailments in canadian soldiers Ottawa: National Research Council of Canada 1947.

66. Helfand AE: Arthritis in older patients as seen in podiatry practices. A pilot survey by the American College of Foot Orthopedists, 1966. J Am Podiatry Assoc 1967, 57:82-84.

67. Horvath F, Bender G, Sillar P, Lengyel E: Arthrosis of the first foot segment in aged patients. $Z$ Orthop Ihre Grenzgeb 1980, 118:251-255.

68. Huang $Z G$, Li Y, Zhang YL, Chi YY, Xu F: Indirect measurement of the foot shape of 319 college students of Han nationality in Liaoning province. Chinese J Clin Rehab 2006, 10:37-40.

69. Hung LK, Ho YF, Leung PC: Survey of foot deformities among 166 geriatric inpatients. Foot Ankle 1985, 5:156-164.

70. Jerosch J, Mamsch H: Deformities and misalignment of feet in children-a field study of 345 students. Z Orthop Ihre Grenzgeb 1998, 136:215-220.

71. Kemp J, Winkler JT: Problems afoot: need and efficiency in footcare London: Disabled Living Foundation 1984.

72. Kilmartin $\mathrm{TE}$, Barrington $\mathrm{RL}$, Wallace $\mathrm{WA}$ : Metatarsus primus varus. $\mathrm{A}$ statistical study. J Bone Joint Surg Br 1991, 73:937-940.

73. Leveille SG, Guralnik JM, Ferrucci L, Hirsch R, Simonsick E, Hochberg MC: Foot pain and disability in older women. Am J Epidemiol 1998, 148:657-665.

74. Levy LA: Prevalence of chronic podiatric conditions in the US. National Health Survey 1990. J Am Podiatr Med Assoc 1992, 82:221-223.

75. Mahrle DA: Foot Health Survey of a Sample Farming Population of the State of Nebraska. J Am Podiatry Assoc 1965, 55:450-453.

76. Marr SJ, D'Abrera HJ: Survey of joint mobility and foot problems of 191 Australian children. J Am Podiatr Med Assoc 1985, 75:597-602.

77. Merrill HE, Frankson J Jr, Tarara EL: Podiatry survey of 1011 nursing home patients in Minnesota. J Am Podiatry Assoc 1967, 57:57-64.

78. Munro BJ, Steele JR: Foot-care awareness. A survey of persons aged 65 years and older. J Am Podiatr Med Assoc 1998, 88:242-248.

79. Oppel U, Bajer D, Wilke U: Epidemiology and early functional treatment of the hallux valgus in juveniles. Orthopadische Praxis 1984, 20:533-537.

80. Podrushniak EP, Marchenko AE: Static deformities of feet in the process of ageing of man. Ortop Travmatol Protez 1980, 9:31-34.

81. Robinson J: The Aldersgate Study Bedford Park, Australia: Flinders Medical Centre 1989

82. Saez Aldana F, Martinez Galarreta MV, Martinez-Iniguez Blasco J: Analysis of falls producing hip fracture in the elderly. Rev Ortop Traumatol 1999, 43:99-106.

83. Schank MJ: A survey of the well-elderly: their foot problems, practices and needs. J Gerontol Nurs 1977, 3:10,12-13.

84. Schnitzer JS, Hoeffler DF: The distribution and etiology of foot disorders in a Navy recruit population. J Am Podiatry Assoc 1974, 64:854-853.

85. Smetisko Z: Malposition of feet in the prone position as the exogenous factor in the formation of hallux vagus in adolescents. Arh Zast 1989, 33:311-317.

86. Spahn G, Schiele R, Hell AK, Klinger HM, Jung R, Langlotz A: The prevalence of pain and deformities in the feet of adolescents. Results of a cross-sectional study. Z Orthop Ihre Grenzgeb 2004, 142:389-396.

87. White EG, Mulley GP: Footcare for very elderly people: a community survey. Age Ageing 1989, 18:276-278.

doi:10.1186/1757-1146-3-21

Cite this article as: Nix et al.: Prevalence of hallux valgus in the general population: a systematic review and meta-analysis. Journal of Foot and Ankle Research 2010 3:21.

\section{Submit your next manuscript to BioMed Central and take full advantage of:}

- Convenient online submission

- Thorough peer review

- No space constraints or color figure charges

- Immediate publication on acceptance

- Inclusion in PubMed, CAS, Scopus and Google Scholar

- Research which is freely available for redistribution

Submit your manuscript at www.biomedcentral.com/submit
Biomed Central 